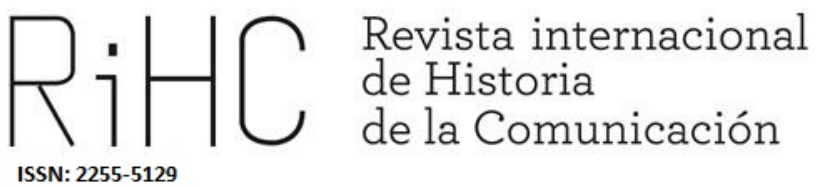

\title{
LA PRENSA ESPAÑOLA EN NUEVA YORK DURANTE EL SIGLO XIX
}

The Spanish Press in New York throughout the Nineteen Century

DOI: http://dx.doi.org/10.12795/RiHC.2019.i12.03

Recibido: 9/10/2018 Aceptado: $11 / 11 / 2018$

Publicado: $15 / 06 / 2019$

Miguel-Angel Hernandez Fuentes Universidad de Salamanca, España miguelangelhernandez@usal.es ORCID (D) 0000-0002-7922-215 
Resumen: Entre la prensa neoyorquina del siglo XIX hubo una serie de periódicos publicados en castellano que nacieron para defender los intereses españoles en la gran ciudad. Se ponían frente al independentismo cubano que también disponía de sus propios medios de expresión o aglutinaban los intereses de los comerciantes españoles. Junto a ellos, otras publicaciones trataron de cohesionar a los diversos grupos de anarquistas, republicanos o librepensadores. También hubo revistas ilustradas y literarias que hicieron de la prensa española en Nueva York un fenómeno muy activo a lo largo del ochocientos. Tras hacer una cata en las diversas cabeceras, con este artículo se ofrece la variedad de posiciones ideológicas que la colonia española tuvo en la citada urbe y se reflejó en la letra impresa. Con ello se trata de ofrecer un marco de referencia para estudios más concretos de cada una de las publicaciones en las que se muestra la variedad cultural de la pequeña colonia hispanoparlante de Nueva York.

Palabras clave: Prensa, Hispanoparlantes, España, Cuba, Nueva York.

\begin{abstract}
Among the New York press of the nineteenth century there was a series of newspapers published in Spanish that were created to defend Spanish interests in the big city. They objected to the Cuban independence movement that also had its own means of expression and shared the interests of Spanish merchants. Along with them, other publications tried to cohere anarchists, republicans or freethinkers' groups. There were also illustrated and literary magazines that made the Spanish press in New York a very active phenomenon throughout the eighteenth hundred. After making an analysis of the various headlines, this article proposes the different ideological positions that the Spanish colony had in the aforementioned city which was reflected in the print. This article aims to provide a frame of reference for in-depth studies of each of the publications that show the cultural variety of the small Spanish-speaking colony of New York.
\end{abstract}

Keywords: Press, Hispano-speakers, Spain, Cuba, New York.

\title{
Introducción
}

El estudio de la masiva emigración de españoles a Hispanoamérica ocurrida durante las últimas décadas del siglo XIX ha postergado el análisis del movimiento migratorio que se originó en la península Ibérica con destino a los Estados Unidos. Es cierto que los españoles asentados en Norteamérica representaban un pequeño porcentaje en este movimiento demográfico y constituían una colonia poco significativa en comparación con los alemanes, irlandeses, rusos o italianos. Las cifras de población son bastante elocuentes. De los tres millones y medio de habitantes que residían en Nueva York al concluir el siglo XIX, ciento ochenta mil habían nacido en Alemania y otros tantos en Irlanda; más de ciento treinta mil llegaron desde Rusia y unos cien mil desde Italia. A esas cifras hemos de añadir a los seiscientos mil neoyorquinos hijos de padres alemanes, al medio millón que habían nacido en una familia irlandesa o a los 
doscientos mil descendientes de italianos o de rusos ${ }^{1}$. Junto a los pertenecientes a otras nacionalidades componían una población foránea que superaba los tres millones de inmigrantes de primera o segunda generación.

En ese conglomerado lingüístico y cultural, los españoles asentados en Nueva York apenas superaban los mil residentes y los cubanos sumaban unos mil quinientos, teniendo en cuenta que esta isla del Caribe perteneció a la monarquía hispánica hasta 1898. Sin embargo, los españoles que eligieron como destino los antiguos territorios coloniales constituyeron un colectivo mucho más numeroso. Más de quinientos sesenta mil españoles se mudaron a Hispanoamérica durante la última década del ochocientos en un movimiento migratorio que siguió creciendo durante la siguiente centuria. Estos datos muestran la insignificancia numérica de la colonia española en Nueva York, aunque, desde su pequeñez, los hispanoparlantes asentados en Manhattan o en Brooklyn fueron capaces de organizarse para defender sus intereses, promover iniciativas benéficas, sociales y culturales (Hernández Fuentes, 2017) e incluso publicar sus propios periódicos a los que vamos a referirnos en este artículo.

En torno a 1830, una serie de medidas económicas y postales impulsaron el desarrollo de la prensa norteamericana que también benefició a los periódicos destinados al público hispanohablante asentado en Nueva York. Algunos nacían vinculados al independentismo cubano y otros se encargaron de defender los intereses españoles, inaugurando una línea continua, aunque zigzagueante, de periódicos editados en español en los Estados Unidos que se ponían al servicio de los diversos intereses comerciales e ideológicos y reflejaban los cambios políticos que se sucedían en el accidentado siglo XIX español.

Disponemos de un amplio catálogo de las publicaciones editadas en español en los Estados Unidos que sin ser definitivas, ofrecen un punto de partida para su clasificación (Kanellos y Martell, 2000). Junto a ellas, los vínculos establecidos a lo largo del siglo XIX entre los independistas cubanos y Nueva York han hecho que exista una amplia base documental en la Biblioteca Nacional de Cuba cuyos índices han sido publicados recientemente y nos permiten caracterizar las publicaciones periódicas más sobresalientes que fueron publicadas por la emigración durante las guerras de independencia (Oliva y Sánchez, 2015).

La digitalización de algunos de los fondos existentes en los diversos archivos y bibliotecas ha permitido su conservación y difusión, facilitando el acceso y la búsqueda. En la New York Public Library se encuentra una base documental que nos permite acceder a las cabeceras conservadas en la colección digital «Hispanic American Newspapers, 1808-1980» cuya consulta ha sido capital para la elaboración de este trabajo. Otros periódicos han sido puestos en la red como La Llumanera de

\footnotetext{
${ }^{1}$ Twelfth Census of the United States, taken un the year 1900, Washington, United States Census Office, 1901.
} 
Nova York, disponible en el Arxiu de Revistes Catalanes Antigues, o El Progreso, accesible en la Hemeroteca Digital de nuestra Biblioteca Nacional. También algunos particulares se han encargado de digitalizar periódicos como El Despertar o El Esclavo disponibles en El Archivo Electrónico Ricardo Flores Magón.

Entre ellos, algunos periódicos han sido objeto de estudios detallados como la prensa anarquista que se ha visto favorecida por el interés que los estudios sobre el anarquismo español han experimentado durante los últimos años, tratando de establecer sus redes internacionales (Alcores, 2013) y rastrear su implantación en los Estados Unidos (Casanovas i Codina, 1989 y Castañeda, 2017). Hoy conocemos bastante bien a los editores y redactores de estos periódicos como Pedro Esteve (Sueiro, 2017) o José Cayetano Campos (Sueiro, 2014). También han sido estudiadas algunas de las publicaciones ilustradas más relevantes como La Revista llustrada de Nueva York (Chamberlin y Schulman, 1976) o La Llumanera de Nova York (Cadafalch, Julian y Salcedo, 1992) y disponemos de algunos trabajos dedicados a los directores más relevantes como José Ferrer de Couto (García González y Roldán de Montaud, 2016) o Nicanor Bolet Peraza (Ameal Pérez, 2015), que estuvieron al frente de El Cronista o de La Revista llustrada de Nueva York.

Fruto del interés suscitado en las últimas décadas por el estudio de las relaciones hispanonorteamericanas, algunas publicaciones se han acercado a la prensa española editada en los Estados Unidos para fijarse en cuestiones sectoriales o analizar las funciones que los periódicos ejercían entre la población norteamericana. Mar Vilar se ha fijado en la aportación que la prensa hizo para la promoción del español en los Estados Unidos, idioma que gozó de un notable interés con la irrupción del Romanticismo y el aprecio que la cultura española y sus costumbres despertó al otro lado del Atlántico (Vilar y Vilar, 1996 y Vilar 2008). Mercedes Caballer dedicó su tesis doctoral al estudio de la prensa norteamericana como medio de promoción de la literatura española e hizo un catálogo de escritores (Caballer Dondarza, 2007).

Sin embargo, aún falta un estudio detallado y un análisis de conjunto de la prensa editada en español en los Estados Unidos que nos permita establecer nexos, proyectos editoriales, intereses económicos y opiniones ante determinados asuntos. Ana María Varela hizo una cata en este asunto con una obra de imprescindible consulta, pero circunscribió su trabajo al último cuarto del siglo XIX (Varela-Lago, 2008). Con este artículo no pretendemos hacer un estudio exhaustivo de todos los periódicos neoyorquinos impresos en español, tan solo presentar las publicaciones más importantes para establecer un marco de referencia que permita un estudio posterior de la prensa española de Nueva York. Hemos querido centrarnos en esta ciudad y no abordar el extenso territorio de los Estados Unidos, por la importancia ocupada por esta metrópoli y por la necesidad de circunscribir el campo de estudio. 


\section{Al servicio de los intereses españoles}

Como era habitual en la sociedad norteamericana, la defensa de los intereses españoles en Nueva York se hizo mediante la letra impresa. Con este propósito comenzaron a publicarse periódicos que, además de servir como vehículo de comunicación e información para la comunidad hispana, contribuyeron a defender sus intereses ideológicos y económicos. Estos diarios, semanarios o revistas eran de fácil edición. Aparecían y desaparecían con mucha fluidez, pues los anuncios abarataban los costes ya que en Nueva York «todo el mundo se anuncia en todos los periódicos» (Álvarez y Grediaga, 1863: 123).

Esta facilidad para editar un periódico no era exclusiva de Nueva York como tampoco lo era el carácter efímero de muchas cabeceras. También en España había cobrado un notable impulso la prensa periódica, especialmente a lo largo del último tercio del siglo XIX. Como ha señalado Celso Almuiña, por aquellas fechas no era preciso contar con una gran estructura para editar un periódico (Almuiña Fernández, 1982: 138). Bastaba disponer de un local donde establecer la administración y la redacción, una plantilla, que, en muchas ocasiones, se limitaba a un puñado de trabajadores poco cualificados, y conseguir una imprenta, propia o alquilada, para llenar las cuatro páginas a que se reducían muchas de las cabeceras.

Además, la prensa prestó un importante servicio a la difusión de la cultura en español por la ciudad, pues en sus oficinas se recibían y vendían libros en castellano, muchos de los cuales procedían de la Habana, y servían para ilustrar a los lectores hispanoparlantes de Nueva York: «En la oficina de este periódico se han recibido catálogos de muchos buenos libros españoles que se hallan de venta en una de las mejores librerías de la Habana» ${ }^{2}$. La oferta no se ceñía solo a un puñado de libros, sino que los lectores disponían de un catálogo para solicitar los ejemplares que quisieran y recibirlos en Nueva York.

\section{Publicaciones en español durante la primera mitad del siglo XIX}

Los primeros periódicos publicados en español en Nueva York estaban vinculados con la causa independentista cubana como El Habanero o El Mensajero Semanal que tenía fuertes raíces en Filadelfia y en Manhattan (Vilar García, 2008: 310). El Habanero fue fundado en 1824 por el padre Félix Varela durante su estancia en Filadelfia,

\footnotetext{
${ }^{2}$ El Redactor, 31 de diciembre de 1831.
} 
trasladándose unos meses después a Nueva York con el propósito de introducirlo en Cuba y alentar así a los independentistas que no disponían de libertad de prensa en la isla. Sin embargo, El Habanero tan solo estuvo dos años en la calle, cesando en 1826. Dos años más tarde, uno de los discípulos y amigos del padre Varela, José Antonio Saco, convenció al sacerdote para que atemperarse el tono beligerante de El Habanero que atemorizaba a los ricos hacendados criollos e imprimiese un periódico de contenido más literario que político, aunque sin renunciar a su carácter independentista (Quintana Suárez, 2011: 11). De este modo comenzó la edición de EI Mensajero Semanal que contaría con la colaboración del escritor Domingo del Monte que había sido discípulo del padre Varela en la Habana. Su primer número vio la luz en Nueva York, el 19 de agosto de 1828, pero los siguientes ejemplares se editaron en Filadelfia adonde se mudó la redacción del periódico hasta el mes de abril de 1829. Ese año, El Mensajero regresó a Nueva York donde siguió publicándose hasta el 29 de enero de 1831 (Rueda Hernanz, 2008: 237-238).

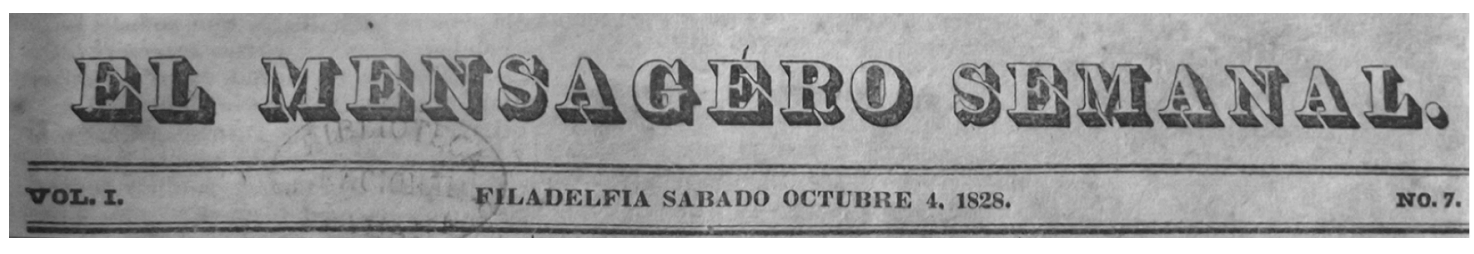

Unos de los números de El Mensajero Semanal, periódico publicado entre 1828 y 1831.

Esta actividad editorial promovida por los independentistas cubanos fue contrarrestada por las fuerzas leales a la corona mediante una serie de periódicos que se imprimían a unas manzanas de distancia. Entre quienes defendían los intereses españoles durante el primer tercio del siglo XIX ocuparon un papel destacado EI Redactor y El Mercurio de Nueva York. El primero surgió a iniciativa de Juan de la Granja, un empresario vasco que emigró a Nueva España en 1814 y, tras la independencia de México y la negativa de España a reconocer el nuevo país, optó por mudarse a los Estados Unidos. Allí regentó una imprenta y una librería con el fin de dar respuesta a los encargos de la Capitanía General de Cuba y del Consulado de España en Nueva York con cuyo titular, Francisco Stoughton, mantenía una cordial relación y algunos negocios comunes (Vilar García, 2008: 312). En otoño de 1827, de la Granja comenzó a publicar El Redactor, contando con la financiación del Consulado español del que se convertía en su portavoz oficioso en América. Desde sus páginas se defendía la españolidad de Cuba y Puerto Rico y «el imposible histórico de que tal dominación fuera restablecida en las independizadas repúblicas de la América continental» (Vilar y Vilar, 1996: 123).

Este apoyo que Juan de la Granja prestaba a la causa de España estaba motivado más por sus intereses empresariales que ideológicos, pues la imprenta se ponía también al servicio del padre Varela, de algunos liberales emigrados y de los agentes iberoamericanos de Nueva York, en especial de los mexicanos con quienes Juan de la 
Granja se sentía muy unido. Tras la muerte de Fernando VII y el fin del absolutismo, la llegada al trono de la regente posibilitó el retorno a España de los liberales emigrados lo que supuso el cierre del periódico que perdía entonces su principal función política y, por tanto, la subvención de Estado español que disfrutaba desde 1828 (Vilar García, 2008: 323). Tras su cese, Juan de la Granja continuó con su actividad editorial publicando El Noticioso de ambos Mundos que estuvo en la calle desde 1836 y 1859 (Kanellos y Martell, 2000: 309). Se trataba de un semanario dedicado al comercio, la agricultura, la política y las bellas artes, donde se defendían los intereses hispanoamericanos frente a las pretensiones expansionistas de los Estados Unidos.

\section{RL REDAOCTOR.}

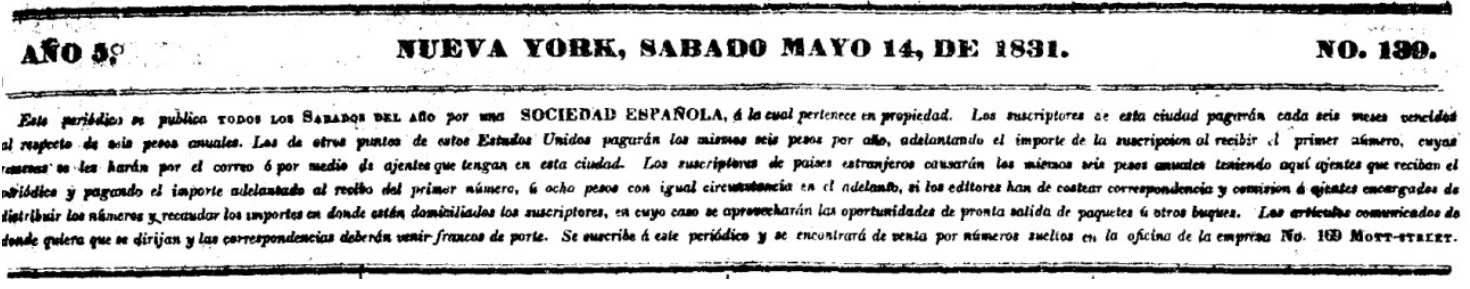

Un ejemplar de El Redactor donde se da noticia de su periodicidad, sociedad editora y otros avisos.

Al mismo tiempo, los comerciantes hispanoparlantes establecidos en Manhattan deseaban disponer de un periódico en el que «primasen los contenidos informativos, económicos, recreativos y culturales sobre los ideológicos, sin dejar por ello de servir a los intereses de España» (Vilar García, 2008: 314). De este se modo fundó El Mercurio de Nueva York cuyo primer número apareció el 10 de mayo de 1828 y el último el 21 de marzo de 1833 (Vilar y Vilar, 1996: 123-124). Según señala Mar Vilar, este periódico fue «un instrumento nada desdeñable de la lengua y de la cultura españolas en ambientes norteamericanos (mercantiles y portuarios sobre todo) conectados a la América hispana» (125). Al principio contó con el apoyo del Consulado español, pero, a medida que fueron aumentando las suscripciones, el periódico se independizó económicamente y se convirtió en una publicación norteamericana que se interesaba más por el Nuevo Mundo que por España. Además, sus alardes independentistas lo pusieron frente al El Redactor con el que polemizó.

\section{Las empresas periodísticas durante la segunda mitad del ochocientos}

Dos décadas después de la fundación de El Mercurio de Nueva York, en 1848, un español procedente de Galicia, Manuel Peña Cagiao, comenzó a editar La Crónica 
convirtiendo a este periódico en el medio oficioso de defensa de los intereses españoles en Manhattan frente a los independentistas cubanos. El periódico se publicaba dos o tres veces a la semana, según la época, cuyo primer número salió en noviembre de 1849 y el último en 1865 tras la muerte de su editor. Esta pérdida hizo necesaria la llegada de otro director que fuese capaz de continuar con la defensa de los intereses españoles en América y, para cubrir esta vacante, fue llamado José Ferrer de Couto, quien tenía tras de sí una amplia trayectoria literaria.

Este historiador y militar español había nacido en 1820 en el Ferrol, la misma localidad natal de su predecesor, Manuel Peña Cagiao, y era hijo de un militar que había combatido en la batalla de Trafalgar. Como su padre, también Ferrer de Couto se introdujo en la marina, ingresando muy joven en la Academia de Pilotos de El Ferrol. En 1844, abandonó su vocación castrense para dedicarse a la carrera literaria, orientando muchas de sus publicaciones a temas relacionados con su profesión militar. En 1851 regresó a la milicia, aunque continuó cultivando su pasión investigadora de la cual surgieron nuevos volúmenes. Retirado finalmente de la vida militar, comenzó una frenética actividad que le llevó por París, Londres y Cuba, defendiendo la raza española y los intereses hispanos en América frente a la doctrina Monroe ${ }^{3}$.

En 1864, Ferrer publicó una polémica obra sobre la esclavitud, que se convirtió en un best seller con más de 24.000 ejemplares editados ${ }^{4}$. En ella se defendía que «la esclavitud de los negros fue en realidad su rescate de sus atroces condiciones en África y que la aplicación de sus fuerzas es un hecho civilizador y humanitario» (Burgoa, 2011: 20). Su edición en inglés y en español favoreció la difusión del texto y avivó la polémica durante la Guerra de Secesión lo que trajo consigo la impopularidad del autor en los centros abolicionistas (Diana, 1874: 619). Esta incursión de Ferrer de Couto en un asunto tan polémico venía motivada por la defensa de los intereses españoles, pues la esclavitud afectaba a los negocios que algunos de sus compatriotas sostenían en las Antillas.

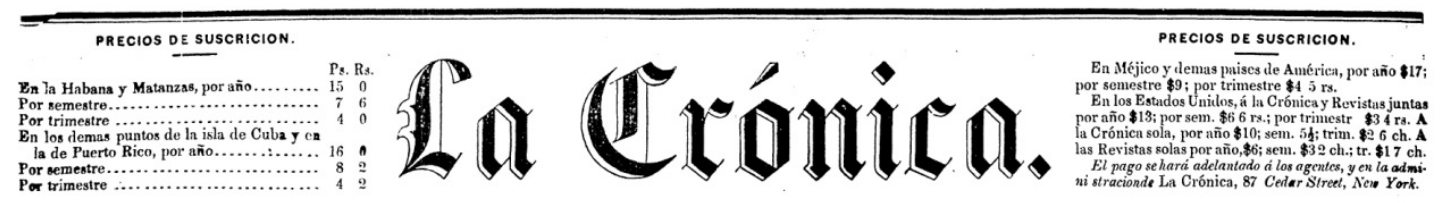

ESPAÑA Y LOS PUEBLOS HISPANOAMERICANOS.

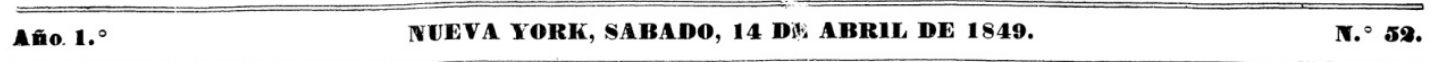

\footnotetext{
${ }^{3}$ FERRER DE COUTO, J. (1859): América y España consideradas en sus intereses de raza, ante la república de los Estados Unidos del Norte, Cádiz, Imprenta de la Revista Médica de Cádiz.

${ }^{4}$ FERRER DE COUTO, J. (1864): Los negros en sus diversos estados y condiciones, tales como son, como se supone que son y cómo deben ser, Nueva York, Imprenta de Hallet; IDEM (1864): Enough of war! The question of slavery conclusively and satisfactorily solved, Nueva York, S. Hallet, Printer.
} 
En 1865, un año después de publicado este opúsculo, fallecía el director de La Crónica de Nueva York. La agilidad que Ferrer de Couto tenía con la pluma y su compromiso en la defensa de los intereses españoles convirtieron a este militar y escritor español en el candidato idóneo para dirigir el periódico. Sin embargo, las dificultades políticas y financieras por las que pasaba La Crónica hicieron que el nuevo director se desentendiera pronto del periódico, vendiéndolo y sustituyendo su cabecera por la de El Cronista. De este modo, Ferrer de Couto trataba de liberarse de las deudas contraídas por la familia de su anterior propietario y comenzaba una nueva etapa estableciendo su sede en los números 64 y 66 de Broadway.
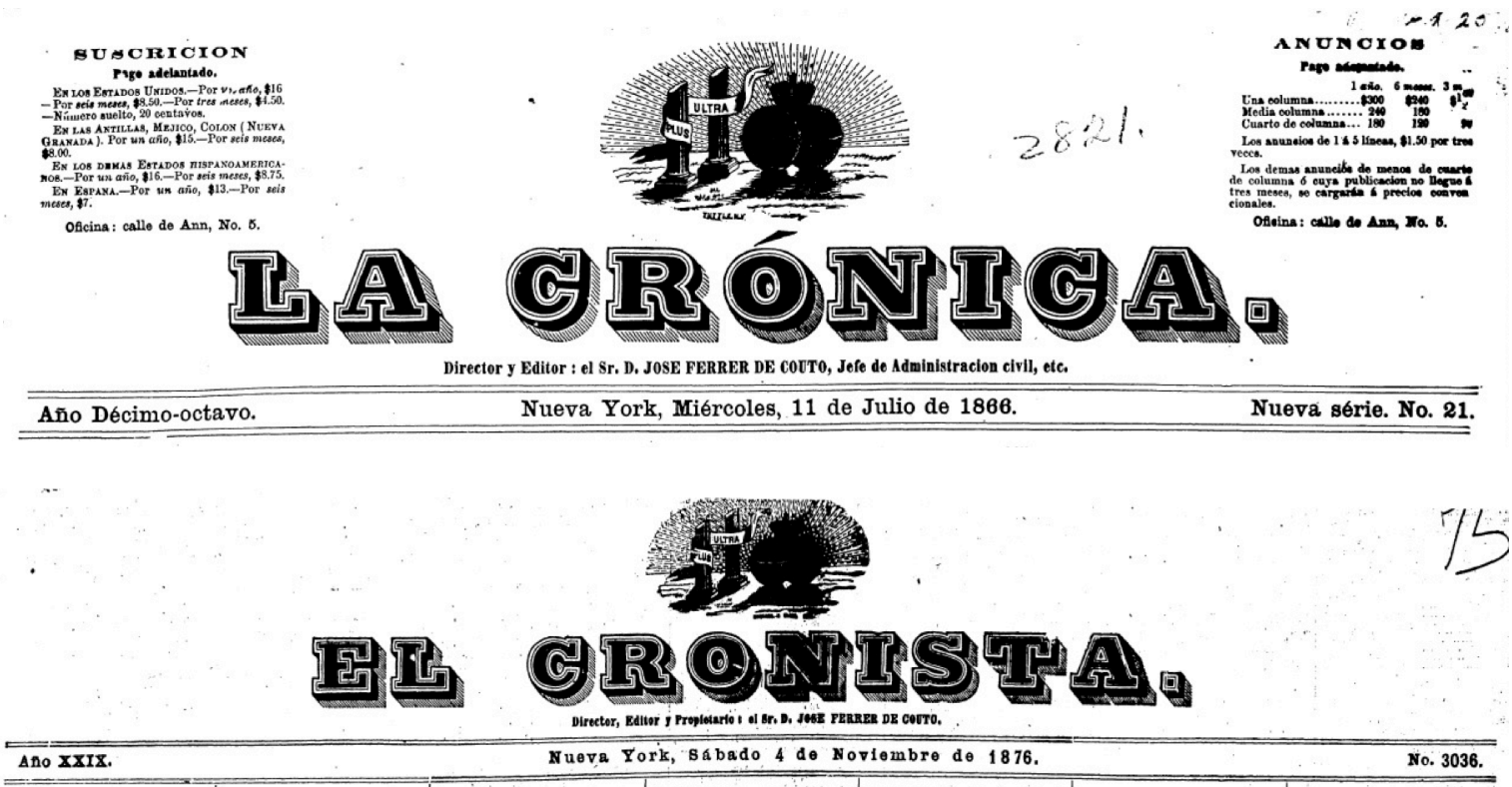

Cabeceras de La Crónica y El Cronista dirigidas y editadas por José Ferrer de Couto.

Como era de suponer, la defensa del españolismo que hizo Ferrer desde las páginas del nuevo periódico no eran del gusto de todos e incomodaba especialmente a los independentistas cubanos que vivían en Nueva York a quienes se tildaba de cobardes, facinerosos y bandidos. Esto hizo que el director de El Cronista sufriera diversos atentados y llegara a batirse en duelo (Burgoa, 2011: 22). La prensa neoyorquina se hizo eco de la pugna que sostuvo con el editor de La Independencia, Juan Bellido de Luna, que concluyó en un lance del que Ferrer de Couto resultó herido en el costado izquierdo.

El patriotismo radical que defendía en sus páginas tampoco agradaba a todos los españoles (García González y Roldán se Montaud, 2016: 65-75), lo que trajo consigo la división entre la comunidad hispanoparlante (Varela-Lago, 2008: 42). Quienes sostenían una postura más acorde con el liberalismo y trataban de conciliar la presencia española en el Caribe con los intereses norteamericanos se distanciaron de 
la línea editorial del periódico. Sin embargo, El Cronista mantuvo la supremacía sobre la prensa española en los Estados Unidos hasta su desaparición en 1877.

Un año antes, en el mes de abril de 1876, dos antiguos empleados de Ferrer de Couto, José G. García y Enrique Muñiz, que se habían encargado de publicar El Cronista durante la estancia de su director en la Habana, fundaron Las Novedades. España y los pueblos hispano-americanos. El nuevo periódico salía a la calle con motivo de la Exposición Conmemorativa del Centenario de la Declaración de Independencia de los Estados Unidos que tuvo lugar en Filadelfia en 1875. El director de El Cronista consideró la creación de este periódico como una conspiración contra su persona y como una traición a España, lo que abrió una larga polémica entre ambas cabeceras que llegó incluso a la edición de unos panfletos donde cada parte defendía su causa ${ }^{5}$.

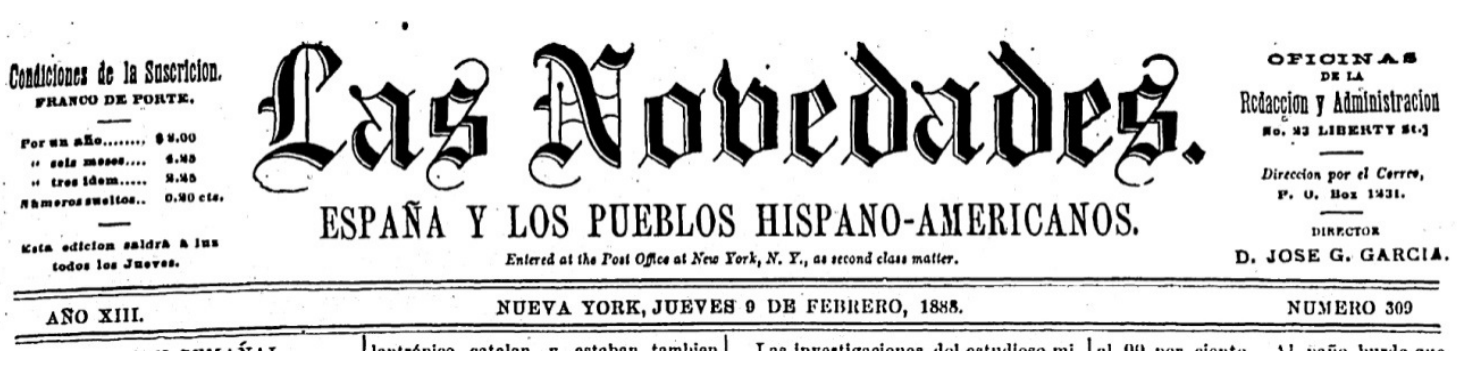

Cabedera de Las Novedades que asume el mismo subtítulo que La Crónica tenía al principio.

Entre ambos periódicos se percibía una concepción distinta de España, de la hispanidad y del papel que los españoles debían jugar en los Estados Unidos. Según Ana Varela Lago, Las Novedades tenía una visión menos estridente del patriotismo que El Cronista, cuyo director solía asociar el liberalismo con el antipatriotismo (VarelaLago, 2008: 42-44). El nuevo periódico asumía una percepción más liberal y pragmática de la política del momento en consonancia con las opiniones de sus compatriotas en los Estados Unidos y en Cuba. Su creador, José G. García, había nacido en Oviedo en 1845 y emigrado a los Estados Unidos en 1860 donde fijó su residencia y contrajo matrimonio (Barrera-Agarval, 2018). Tenía una visión más atemperada del papel que debía jugar España ante la nueva situación política y trataba de facilitar el acercamiento entre los españoles y sus antiguas colonias con el fin de estrechar lazos entre todos aquellos que compartían la misma lengua. A todos les interesaba unir sus fuerzas para promover intereses comunes en vez de enfrascarse en rencillas $y$ acusaciones. El otro colega, Enrique Muñiz, colaboró inicialmente con José G. García en

\footnotetext{
${ }^{5}$ Ante las acusaciones formuladas desde El Cronista, los redactores de Las Novedades respondieron con un folleto de veintiséis páginas: MUÑIZ E. y GARCÍA, J.G. (1876): Nuestra defensa. Contestación a los alevosos y embozados ataques que don José Ferrer de Couto ha dirigido en El Cronista contra don Enrique Muñiz y don José García, Nueva York. A este pliego el director de El Cronista replicó con otro panfleto de cien páginas: FERRER DE COUTO, J. (1876): La Verdad. Folleto en defensa de las injurias que le ha dirigido por escrito don Enrique Muñiz, Nueva York.
} 
la fundación de Las Novedades, polemizando agriamente con Ferrer de Couto, pero en enero de 1878 abandonó este proyecto editorial y se marchó a la Habana ${ }^{6}$. Durante su estancia en Cuba, que apenas duró un año, Muñiz fundó los periódicos La Voz de Cuba y El Diario de Cienfuegos. Posteriormente, en enero de 1879, se mudó a México donde continuó con su carrera al frente de La Voz de España. En México Enrique Muñiz estuvo muy implicado con la masonería (Kanellos, 2017: 14) y sostuvo varias polémicas periodísticas, siendo una de las más conocidas la que le enfrentó con Ignacio Manuel Altamirano.

Mientras tanto, en Nueva York, la pugna entre los periódicos aludidos, El Cronista y Las Novedades, concluyó con la muerte de José Ferrer de Couto el 2 de julio de $1877^{7}$. Tras esta fatídica pérdida, Las Novedades compró la cabecera de su rival con el deseo de aprovecharse de la supremacía que aquel periódico ejercía sobre la prensa hispanoparlante de la ciudad. Las Novedades comenzó a presentarse como "sucesora de La Crónica y El Cronista», argumentando que existía desde el año 1848 y presentándose como «el periódico más antiguo de los publicados en Nueva York, órgano de España y los pueblos hispanoamericanos» (Beldad, 1903: 120). Salía a la calle los jueves con dieciséis páginas y ocho dólares de coste anual, cuya imprenta se ubicaba en el 108 de Fulton Street. Con esta tarjeta de presentación pretendía mantener a todos los lectores y suscriptores que sostenían los diarios precedentes y poner fin a la polémica que les había enfrentado durante los últimos años.

De este modo, Las Novedades se hizo con el liderazgo de la prensa española en los Estados Unidos donde se mantuvo más de cuarenta años. En su época de máximo apogeo llegó a editar 2.800 ejemplares que se distribuían por Cuba, Puerto Rico, México y por las diversas repúblicas americanas, convirtiendo al periódico en un poderoso medio de influencia. Su capacidad de movilizar a la opinión pública hizo que el gobierno español le prestara su apoyo económico, otorgando a su director un subsidio de doscientos cincuenta dólares. Posteriormente, ante la postura favorable que la opinión pública norteamericana sostenía respecto a la causa cubana, surgió el deseo de captar al lector angloparlante e influir en su opinión. El gobierno español duplicó entonces el subsidio entregado a Las Novedades cuyo montante fue utilizado para sacar a la calle una edición en inglés. Con ello se materializaba el propósito que el embajador español Enrique Dupuy de Lôme había manifestado en un telegrama a Martínez Campos de convertir la prensa en la mejor arma para combatir a los independentistas cubanos en los Estados Unidos (Varela-Lago, 2018), aunque hoy ya sabemos que su artillería de la letra impresa tuvo muy pocos resultados.

\footnotetext{
${ }^{6}$ The New York Tribune, 7 de marzo de 1878.

7 «Death of a Spanish journalist. Jose Ferrer de Couto, editor of the El Cronista, dies suddenly sketch of his life», The New York Times, 4 de julio de 1877, p. 5.
} 
Con el propósito de informar al embajador de todo aquello que se fuera publicando en los Estados Unidos sobre Cuba, divulgar cartas en los diarios norteamericanos y traducir al inglés la documentación oficial española, en el mes de diciembre de 1895 se fundó la Associated Spanish and Cuban Press que estuvo financiada por el Gobierno español y liderada por una junta presidida por Arturo Cuyás e integrada por su hermano Antonio como tesorero y Luis V. Abad como secretario. Su presidente, Arturo Cuyás (Barcelona 1845-Madrid 1925), jugó un destacado papel en la prensa neoyorquina en español, poniéndose al frente de diversos proyectos periodísticos. Había desembarcado en Nueva York el 5 de diciembre de 1862 para reunirse con su padre que regentaba el Hotel Barcelona desde su reciente apertura en el número 23 de Great Jones Street. Aquel joven escritor comenzó muy pronto su carrera periodística como redactor en La Crónica de Nueva York donde empezó a trabajar en 1864. Asimismo, fue corresponsal de diversos diarios españoles en los Estados Unidos como La Época o El Imparcial y colaborador de La Revista llustrada de México o La Voz de Cuba de la Habana. En 1874 fundó la Llumanera de Nova York, una revista ilustrada donde se manifiesta la vitalidad que la colonia catalana tenía en Manhattan a la cual nos referimos en el apartado siguiente. Dos años más tarde, en 1876 publicó un Diccionario español-inglés e inglés-español, de amplia difusión, que fue adoptado oficialmente en las academias militares y navales $y$ en las universidades norteamericanas. En diciembre de 1895 se puso al frente de la citada Associated Spanish and Cuban Press que mantuvo una intensa actividad durante las postrimerías del ochocientos.

Desde unas oficinas localizadas en los primeros números de Broadway, junto a Bowling Green, los responsables de esta agencia española se encargaban de elaborar con bastante regularidad un dossier de prensa del que, según Ana Varela, se conservan cuatro volúmenes; enviaban artículos a los diversos periódicos neoyorquinos con el fin de crear una opinión proclive a los intereses españoles y editaron algunos libros como The New Constitutional Laws for $\mathrm{Cuba}^{8}$ con los que se pretendía informar directamente de la legislación emitida por el gobierno español respecto a la cuestión cubana y liberar estas leyes de la intoxicación a la que se veían sometidas por la opinión pública norteamericana. No obstante, a pesar de sus esfuerzos, sabemos que la eficacia de estas medidas fue muy limitada y que los Estados Unidos mantuvieron una actitud proclive a los independentistas cubanos a quienes apoyaron finalmente en la guerra.

\footnotetext{
${ }^{8}$ The New Constitutional Laws for Cuba. Text of the Recent Measures for the Self-Government of the Island with Comments Thereon. Also a Brief Review of the Evolution of Spanish Colonization and a Statistical Comparison of the Progress of Cuba under Spanish Rule with That of Independent SpanishAmerican Countries, Nueva York, Associated Spanish and Cuban Press, 1897; Text of the New Reform Measure for the Island of Cuba: "Expository Preamble» and "Royal Decree», Nueva York, Associated Spanish and Cuban Press, 1897.
} 


\section{La prensa ilustrada y las revistas literarias}

Una de las características del periodismo español del último tercio del siglo XIX fue la disminución de la prensa política en favor de otras publicaciones más centradas en los intereses materiales y el crecimiento de la prensa especializada (Almuiña Fernández, 1982: 138). No obstante, los periódicos políticos e ideológicos siguieron ejerciendo su primacía sobre el resto de publicaciones, máxime en una ciudad como Nueva York donde la cuestión cubana era tan candente. Sin embargo, junto a estos periódicos surgieron otras empresas que dotaron a la profesión de una mayor variedad de contenidos y propósitos, de los cuales algunos asumieron una misión pedagógica, literaria o de entretenimiento. Los periódicos ilustrados estampaban en sus páginas grabados costumbristas, difundían las bellezas del país o mostraban la variedad cultural del planeta. Otros periódicos comenzaron a propagar la literatura con el deseo de llegar a un público más amplio. Unos y otros solían reflejar los intereses de la burguesía y su particular cosmovisión (Bozal Fernández, 1979: 11). Entre la prensa gráfica editada en España tuvo una especial relevancia La Ilustración Española y Americana fundada en 1869 y dirigida a los hispanoparlantes de ambas orillas del océano (Adams Fernández, 1992: 128).

Aunque la citada revista mantuvo la supremacía sobre el resto de publicaciones gráficas, también en Nueva York surgieron otros proyectos editoriales que podemos incluir entre la prensa ilustrada. Uno de los principales promotores de este tipo de publicaciones en Manhattan fue Juan Ignacio de Armas y Céspedes, un escritor cubano que emigró a Nueva York en 1869, donde dirigió La América: Periódico Quincenal Ilustrado, editado por Hallet \& Breen en 1871, La América Ilustrada entre 1872 y 1873 , y, posteriormente, fundó y dirigió el periódico literario El Ateneo (1874-1875) ${ }^{9}$.

Entre estas publicaciones literarias e ilustradas, tuvo una especial relevancia La Revista Ilustrada de Nueva York que estuvo en la calle entre 1886 y 1893. Su precedente inmediato fue la Thurber, Whyland and Company's Review una publicación que nacía con el deseo de difundir la actividad de esta empresa radicada en Manhattan que pasaba por ser una de las más antiguas dedicadas a la venta al por mayor de comestibles y gozaba de "una reputación envidiable como uno de los mayores importadores de café y té del país», (Schulman y Zelizer, 2017: 13). Al frente de la sección hispanoparlante se puso a Elías de Losada Plisé (1848-1896), un empresario panameño con raíces españolas que también pertenecía al sector de la importación. Su abuelo, Juan Miguel de Losada había nacido en Málaga en 1763, pero emigró a Florida como oficial primero de la Real Tesorería donde nació su hijo Cristóbal de Losada en

\footnotetext{
${ }^{9}$ No fue el único. Disponemos de un amplio elenco de publicaciones gráficas en español editadas en Nueva York durante la segunda mitad del siglo XIX cuyo análisis desborda este trabajo (Kanellos y Martell, 2000: 143-275).
} 
1812. Tras la compra del territorio por los Estados Unidos, la familia se mudó sucesivamente a Nueva Orleans, Cuba y finalmente a Panamá donde nació Elías. Este joven abandonó su país con doce años y, tras un recorrido por diversos lugares del mundo que le otorgaron su particular visión cosmopolita, recaló en Nueva York donde, junto a Tomás Asensio, fundó la Compañía de importación y exportación de productos Asensio-Losada en 1877. Tras unos años de actividad conjunta, en 1883 o 1884, esta compañía se fusionó con la firma Thurber, Whyland and Company Importers, Manufacturers and Grocers (Chamberlin y Schulman, 1976: 22).

En este momento, Losada asumió la dirección de la Thurber, Whyland and Company's Review y decidió mudar su nombre pasando a llamarse La Revista Mercantil de Precios Corrientes del Mercado de Nueva York. Posteriormente, Losada decidió acortar el nombre y la publicación salió a la calle en el mes de julio de 1885 como La Revista Mercantil de Nueva York cuya dirección se puso en manos del escritor venezolano Nicanor Bolet Peraza entre 1885 y 1890 (Ameal Pérez, 2015: 77-91). En 1887 el periódico mudó una vez más el nombre, abandonando la impronta comercial de su cabecera que adquirió un matiz más literario: La Revista llustrada de Nueva York. En una breve nota editorial se dio cuenta de esta nueva denominación: «aunque sirviendo como servimos una sección comercial muy detallada, nuestro primordial objeto es más amplio y trascendental» ${ }^{10}$. Esta misión no era otra que la "particular atención a los asuntos literarios (...) de los más renombrados líricos de España y de América» (Chamberlin y Schulman, 1976: 4).

En 1890 el periodista y poeta nicaragüense Román Mayorga Rivas asumió la dirección de la revista sustituyendo a Nicanor Bolet que había sido nombrado ministro plenipotenciario y enviado extraordinario de Venezuela en Washington. Un año después, se puso al frente de la misma el historiador colombiano Ricardo Becerra, pero en diciembre de 1892, su fundador y editor Elías de Losada decidió venderla por diez mil dólares a Andrés F. Power. Esta transacción debilitó la revista, que inició entonces un periodo de decadencia, dejando de publicarse un año más tarde.

Durante los años que se mantuvo en la calle la revista se convirtió en un baluarte para la defensa de los intereses culturales, literarios y empresariales de los países latinoamericanos, protegiendo al mismo tiempo la identidad propia de cada uno frente al proteccionismo estadounidense que caracterizó su política exterior (Caballer Dondarza, 2007: 124). En el terreno intelectual, sus editores se alineaban con la filosofía positivista y ponían la publicación al servicio de la causa de la civilización y del progreso, defendiendo unos sistemas sociales caracterizados por el orden y la estabilidad (Chamberlin y Schulman, 1976: 4). Al mismo tiempo, la revista se convirtió en una plataforma importante para la promoción de la literatura española y estableció

\footnotetext{
${ }^{10}$ "Nuevo título», La Revista Ilustrada de Nueva York, diciembre de 1886.
} 
una comunicación abierta con diversas cabeceras publicadas en inglés como el Herald o el Sun y con otras que llegaban desde España (Caballer Dondarza, 2007: 129). Aunque quienes estuvieron al frente no fueron españoles sino empresarios y escritores hispanoamericanos, en sus páginas aparece la firma de algunos literatos como Emilio Castelar, Benito Pérez Galdós, Mariano José de Larra, Emilia Pardo Bazán, Juan Valera o Ramón María del Valle-Inclán. Algunos redactaron sus textos especialmente para La Revista llustrada de Nueva York como Emilia Pardo Bazán que escribió tres o Juan Valera que publicó siete (Chamberlin y Schulman, 1976: VII). No en vano, esta revista pretendía unir a todos los hispanoparlantes que compartían una misma lengua para resistir frente a la civilización anglosajona que amenazaba con disolver a la cultura hispana (Chamberlin y Schulman, 1976: 8).

Entre los grupos regionales de España que tuvieron una identidad más marcada en el conjunto de la emigración española estaban los catalanes. Esta comunidad lingüística fundó una coral, dispuso de establecimientos hoteleros y comisionistas propios, tuvo un servicio de distribución de libros para sus lectores catalanoparlantes ${ }^{11}$ y llegó a editar un periódico titulado La Llumanera de Nova York. El fundador y director de esta revista fue Arturo Cuyás, a quien nos hemos referido anteriormente con motivo de la Associated Spanish and Cuban Press. Firme defensor del dominio español sobre la isla de Cuba y del emperador Maximiliano de México, Cuyás sostenía una política españolista y, al mismo tiempo, lideraba el regionalismo catalán en Nueva York, promoviendo su lengua y su cultura en la diáspora y defendiendo los intereses de la burguesía catalana (Varela-Lago, 2008: 38). En 1874 fundó la Llumanera de Nova York, que se presentaba ante la sociedad neoyorquina como una "revista catalana de noticias y humor ${ }^{12}$ con la que se pretendía preservar la lengua y la cultura de los catalanes que vivían en Nueva York y en otros lugares donde la revista disponía de agentes comerciales (Caballer Dondarza, 2007: 104-105). A partir del número 51 editado julio de 1879, la cabecera perdió el genitivo de Nova York y pasó a denominarse tan solo La Llumanera. Además, en ese momento la revista modificó el grabado de la mancheta y perdió el subtítulo de Revista Catalana de Novas y Gresca ${ }^{13}$.

Con el pseudónimo de "Lo Pampol», Arturo Cuyás firmó numerosos artículos a lo largo de los siete años que la revista se mantuvo en la calle, pero también colaboraron una larga nómina de escritores como Frederic Soler, Francesc Camprodon, Conrad Roure, Emili Coca Collado en incluso Jacinto Verdaguer o Víctor Balaguer, siendo el periodista y dramaturgo catalán Rosendo Arús Arderiu el que aparece con más frecuencia (Cadafalch, Julián y Salcedo, 1992: 107). Para su sostenimiento económico, contaron con la colaboración de Emilio Puig, un hombre de negocios oriundo de Cataluña, pero

\footnotetext{
${ }^{11}$ La Llumanera de Nova York, mayo de 1875, p. 8.

${ }^{12}$ La Llumanera de Nova York, noviembre de 1874, p. 2.

${ }^{13}$ La Llumanera, julio de 1879, p. 1.
} 
afincado en Nueva York donde poseía una compañía dedicada a la importación de productos.

Aunque desde el principio la publicación nació con la pretensión de ser una revista ilustrada, a partir del número 61 de mayo de 1880 puede comprobarse que la parte artística adquiere una mayor relevancia. Al frente de esta sección ilustrada estaba Felip Cusachs, un artista natural de Louisiana que había nacido en el seno de una familia de inmigrantes catalanes establecida en los Estados Unidos durante los años treinta del ochocientos. Pariente del pintor Josep Cusachs, Felip estampó sus dibujos en La Llumanera de Nova York y trabajó en otros periódicos ilustrados como The Daily Graphic. Junto a él colaboraron otros artistas como Josep Lluis Pellicer, Tomás Padró o Antoni Vilanoba y participaron algunos ilustradores norteamericanos como Alfred Brennan y Robert Blum. La mayoría eran representantes de la plástica catalana del momento lo que permitió que en La Llumanera de Nova York se reflejara el movimiento artístico y cultural que va desde el tardorromanticismo, al realismo y al premodernismo (Cadafalch, Julian y Salcedo, 1992: 109).

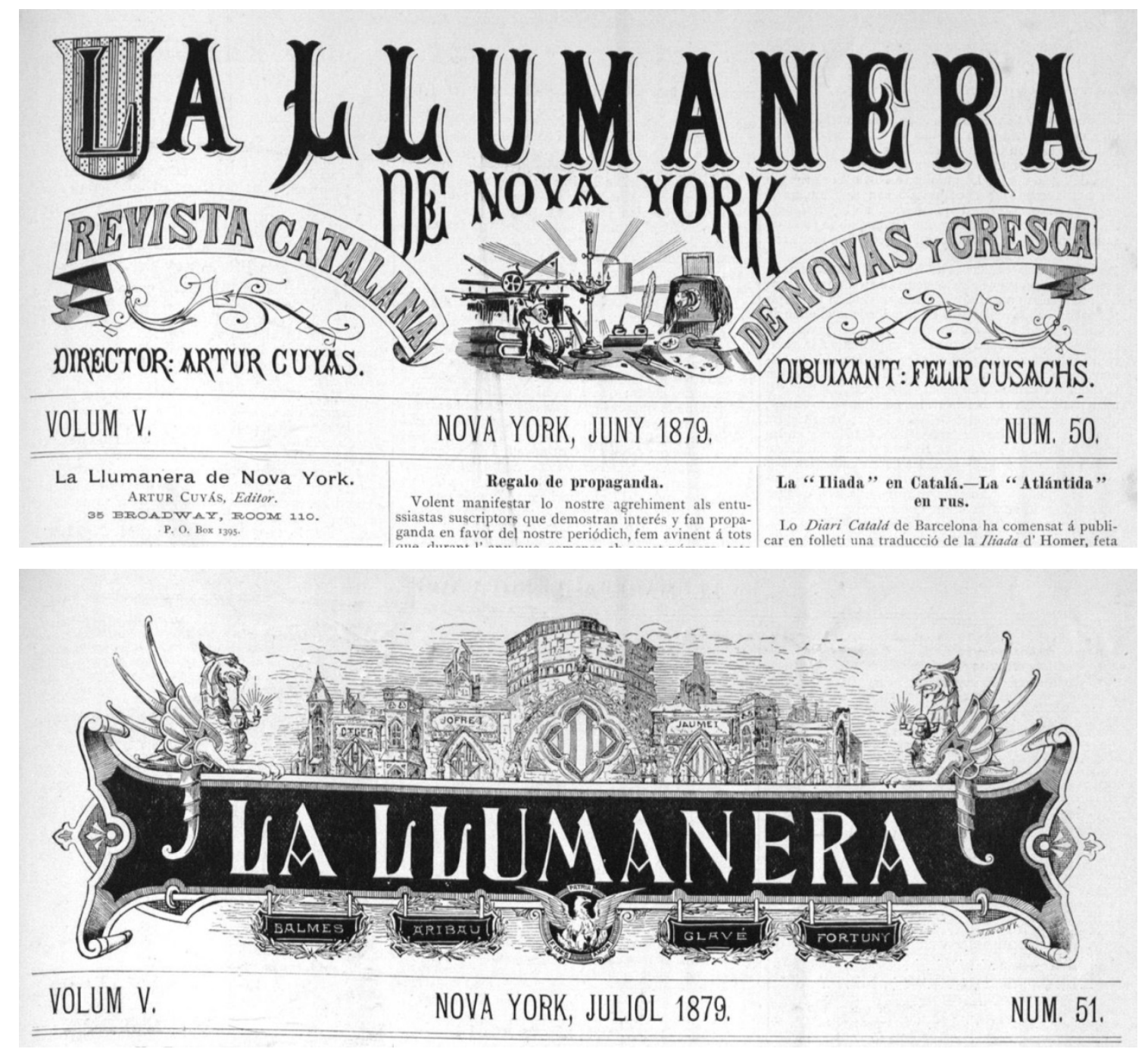

Última cabecera de La Llumanera de Nova York y primera de La Llumanera. 
El 5 de febrero de 1875 comenzó a publicarse La Ofrenda de Oro. Repertorio Ilustrado de Artes y Literatura cuya edición corría a cargo de A. G. Dickinson y estaba financiada por la New York Life Insurance Company, una compañía americana de seguros que también disponía de oficinas en Madrid y Barcelona ${ }^{14}$. A lo largo de sus treinta páginas y ocho números anuales, la revista tenía una vocación literaria y estaba dedicaba principalmente a la narrativa, aunque también se incluían en ella algunos poemas (Caballer Dondarza, 2007: 112). En sus páginas escribieron asiduamente José Martí, Juan Antonio Pérez Bonalde o Rubén Darío y se reprodujeron algunos textos de Emilio Castelar, Benito Pérez Galdós o Gustavo Adolfo Bécquer.

\section{Republicanos, librepensadores y anarquistas en la prensa}

Dos periódicos defendieron en Nueva York el republicanismo español y el librepensamiento. El primero era La Federación. Periódico español republicano, que tuvo una periodicidad quincenal, cuyo director, Juan B. Martínez, lo lideró entre 18731875. Una década después, en 1884, un pontevedrés llamado Ramón Verea comenzó una línea editorial novedosa respecto a los periódicos editados hasta la fecha. Este inmigrante gallego llegó a Nueva York en 1865 donde ejerció como profesor de español y traductor e hizo sus pinitos como inventor de aparatos mecánicos. En 1880 inauguró «El Polígloto», una imprenta donde cuatro años más tarde comenzó a publicar El Progreso. Con esta revista se abría una nueva vía en el espectro político de la prensa neoyorquina en español que se alineaba con el librepensamiento y se manifestaba muy crítico con la monarquía española y con la política de Cánovas del Castillo (Varela-Lago, 2008: 47-48). Desde su posición ideológica, Ramón Verea alimentaba el anticlericalismo y presumía de su independencia, denunciando que los periódicos que vivían de la subvención eran deudores de sus patrocinadores ${ }^{15}$.

\footnotetext{
${ }^{14}$ La Ofrenda de Oro. Repertorio Ilustrado de Artes y Literatura, 16 (1892), última página.

${ }^{15}$ «Primer aniversario», El Progreso, diciembre de 1884, p. 209.
} 


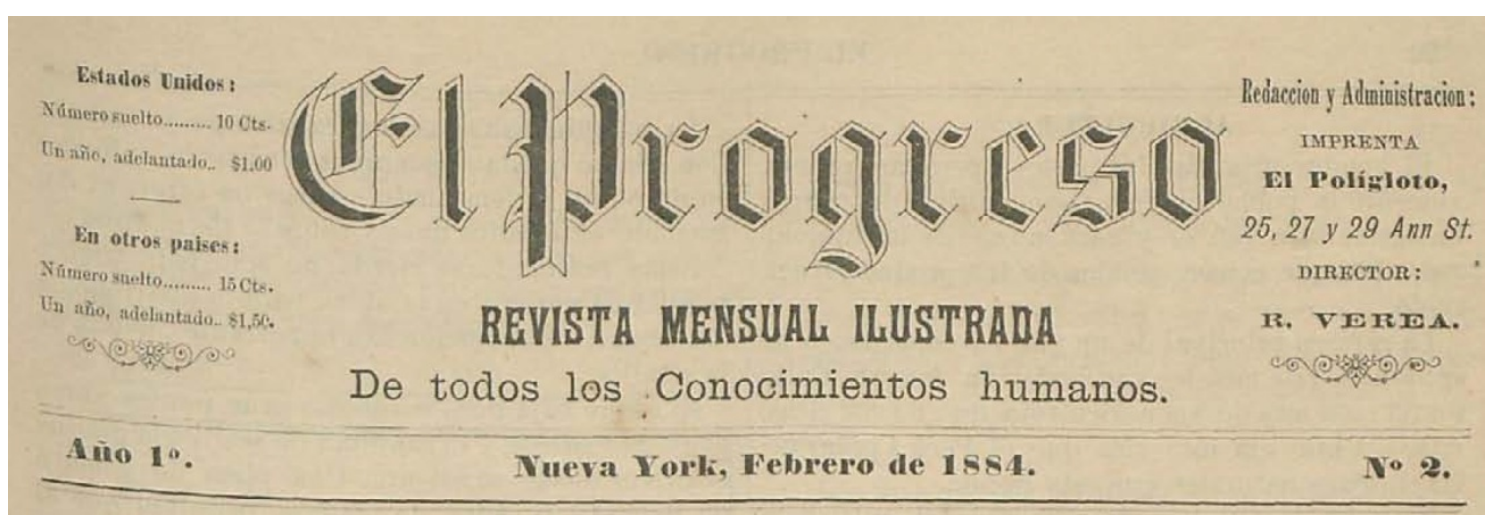

Uno de los primeros números de El Progreso.

Respecto a la cuestión cubana, Verea se mantenía muy distante de los independentistas a quienes responsabilizaba de buena parte de los males padecidos por la isla: "La Gran Antilla, tan rica y tranquila antes de la insurrección de Yara, yace hoy convulsa y arruinada (...) Los que claman por otra rebelión podrán llamarse patriotas: para nosotros son los peores enemigos que el pueblo de Cuba tiene ${ }^{16}$. Sin embargo, reclamaba también una mayor honestidad y rectitud por parte de los dirigentes españoles que debían facilitar mayores cotas de libertad.

En 1888 Ramón Verea denunció el contrabando y la corrupción que reinaba en la administración española de Cuba, lo que desató una virulenta respuesta por parte de Las Novedades, iniciándose con ello una batalla periodística entre ambas cabeceras. En 1895 Verea se mudó a Guatemala y, en 1897, trasladó su domicilio a la República Argentina donde continuó publicando el periódico hasta 1899 en que murió.

También los anarquistas tuvieron su propio periódico. En 1890 un pequeño grupo de obreros de origen español y cubano, empleados en las factorías de tabaco de Brooklyn, pusieron en marcha El Despertar cuyas oficinas radicaban en el número 105 de Fulton Street. Sin embargo, dadas las peculiares condiciones de este grupo anarquista, el periódico hubo de mudar su sede en diversas ocasiones, primero al número 181 de Adams Street, donde se mantuvo durante cinco años, y en 1897 al 124 de Fulton Street. Al año siguiente la administración se mantuvo en Brooklyn, en el 1255 de la Quinta Avenida, pero la redacción se mudó a Paterson, New Jersey, una localidad que era denominada por Pedro Esteve como «la Roma del anarquismo» dado el fuerte arraigo que este movimiento tenía entre los trabajadores de la industria sedera de la ciudad (Casanovas i Codina, 1989: 33). Con esta localidad quedó vinculado el periódico durante sus últimos años, cuya redacción pasó por el 350 Clay Street, el 99 de Madison y el 159 de Mercer Street.

\footnotetext{
${ }^{16}$ «Cuba», El Progreso, marzo de 1884, p. 56.
} 


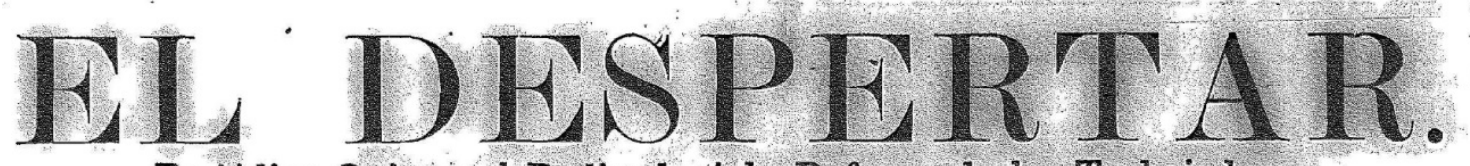

Periódico Quincenal Dedicado á la Defensa de los Trabajadores.

\begin{tabular}{|c|c|c|c|}
\hline AÑo 1. & NEW YORK, AGOST & CO $1^{\circ} \mathrm{DE}=189 \mathrm{i}$ & NUMERO I5. \\
\hline $\begin{array}{c}\text { REDACTOR: } \\
\text { L U I S B A R C I A. } \\
\text { ADMINISTRADOR: } \\
\text { M. M. A B E L L Lo. } \\
\text { Directión ror CORREO;--No. Iós Fulton Strcet. } \\
\text { BROOKLYN. }\end{array}$ & 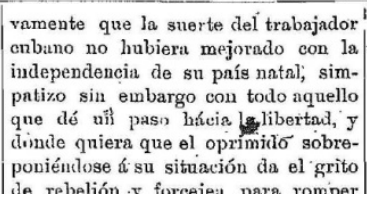 & $\mid \begin{array}{l}\text { Los aristócratas insurrectos habíau } \\
\text { completado su obra. } \\
\text { Crêgeron fácil posesionarse del Po- } \\
\text { der una veż heeha la independencia, y } \\
\text { fueron á la reyolución, pero tan pron- } \\
\text { o oómo se convencieron de que el } \\
\text { elemento radical compuesto de traba- } \\
\text { indores blancos v de color. les arreba- }\end{array}$ & 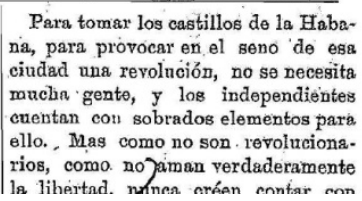 \\
\hline
\end{tabular}

En las páginas del periódico se editaban artículos de los líderes del anarquismo hispano y en la redacción se traducían e imprimían los escritos de Bakunin, de Kropotkin o de Reclus, formando parte de una biblioteca que se convirtió en un medio capital para la difusión del anarquismo entre los trabajadores hispanoparlantes. Su fundador, José Cayetano Campos, era un impresor cubano que emigró a los Estados Unidos en 1877 donde muy pronto se convirtió en el líder de la Unión de Torcedores de Cigarros entre los que difundió sus ideales anarquistas (Castañeda, 2017: 78-79). En 1887, Campos se convirtió en el corresponsal del diario anarquista de Barcelona El Productor. En 1890 llegó a Nueva York Luis Barcia, otro destacado líder del anarquismo español que había nacido en Bilbao, pero había establecido vínculos con los negocios tabaqueros de Cuba y Tampa en los años previos a su establecimiento en Brooklyn. Ambos líderes obreros, junto a un notable grupo de activos anarquistas de la colonia hispanoparlante pusieron en marcha El Despertar. Periódico quincenal dedicado a la defensa de los Trabajadores. En 1892 el periódico hizo notoria su identidad ideológica, sustituyendo el subtítulo anterior por el de Periódico Anarquista.

A estos promotores del periódico se sumaron otros anarquistas llegados allende los mares como Pedro Esteve y Adrián del Valle. El primero era un activista que había nacido en Barcelona en 1865 y se había integrado muy tempranamente en la lucha obrera, siendo uno de los redactores más jóvenes del periódico anarquista El Productor de Barcelona. En su ciudad natal pudo conocer las luchas obreras sostenidas en los Estados Unidos gracias a las crónicas enviadas por el corresponsal de Nueva York José C. Campos «que causaron en el proletariado barcelonés una impresión profunda y duradera» (Sueiro Seoane, 2017: 79) ${ }^{17}$. En 1892 Esteve emigró a los Estados Unidos con el propósito de reforzar la redacción de El Despertar de Brooklyn. Rápidamente se puso en contacto con el grupo anarquista local y, a finales de ese mismo año, había

\footnotetext{
${ }^{17}$ Esta investigadora ha tratado de mostrar en varios artículos las redes transnacionales que vinculaban a los anarquistas de diversas nacionalidades y ha señalado de modo especial los vínculos existentes entre el diario El Productor de Barcelona y El Despertar de Nueva York que compartieron crónicas y redactores.
} 
asumido el liderazgo del movimiento y la dirección del periódico. Posteriormente, Esteve se mudó a Tampa donde fundó El Esclavo, otro periódico anarquista de características semejantes que también tuvo un notable éxito y una proyección internacional (Sueiro Seoane, 2018: 121-140). En 1895 Esteve regresó a Nueva York donde asumió nuevamente la dirección de El Despertar que se mantuvo en la calle hasta 1902.

El Despertar fue siempre un periódico pequeño, de tan solo cuatro páginas, que se editaba quincenalmente, y que por su tamaño y periodicidad no podía competir con Las Novedades o El Progreso. Tampoco era esta su pretensión, pues el diario anarquista tenía como fin la movilización de la clase trabajadora y no la de convertirse en un diario de información generalista, aunque no faltaron las polémicas mutuas. En 1891, el diario anarquista acusaba a Ramón Verea, director de El Progreso, de haber obligado a un operario a marcharse de su casa cuando este le reclamó parte de su trabajo: "No nos extraña ahora que el señor Verea clame por la harmonía entre el capital y el trabajo. iYa lo creo! La harmonía del tigre y de la víctima ${ }^{18}$. Respecto a Las Novedades, la posición que este influyente periódico tenía sobre el anarquismo quedó patente en uno de sus artículos, donde se calificaba a los anarquistas como «un peligro gravísimo para toda la nación» y se afirmaba taxativamente, "desde el momento en que se convierten en asesinos ya solo queda una cosa que hacer y cuanto antes se haga mejor» ${ }^{19}$. El cierre abrupto que sufrió El Despertar en 1902 marcó el fin de una época vibrante del movimiento anarcosindicalista que obtuvo un cierto éxito entre los inmigrantes de habla española establecidos en Brooklyn (Castañeda, 2017: 78).

Como Esteve, Adrián del Valle también era originario de Barcelona (1872) y allí comenzó su aventura periodística. Tras recorrer algunos países europeos, emigró a los Estados Unidos donde asumió la dirección de El Despertar entre 1893 y 1894, durante la estancia de Esteve en Cuba. Posteriormente, del Valle se mudó a Tampa donde colaboró con Esteve en la redacción de El Esclavo. Durante su estancia en Florida del Valle asumió el populismo anticolonial de José Martí lo que le empujó a mudarse a la Habana en 1895 para apoyar la causa independentista. Ante la imposibilidad de unirse a los mambises, regresó a Nueva York, donde fundó El Rebelde en 1898. En las páginas de este periódico se defendía la participación de los anarquistas en la guerra independentista de Cuba a diferencia de la postura mantenida por El Despertar, que sostenía la neutralidad de los obreros frente al conflicto. La sede de El Rebelde quedó establecida en el número 116 de High Street de Brooklyn y, para su puesta en marcha, contó con la colaboración de José Cayetano Campos y de Luis Barcia. Sin embargo, esta nueva empresa periodística tuvo un breve recorrido.

\footnotetext{
${ }^{18}$ El Despertar, 15 de diciembre de 1891, p. 4.

19 "La plaga anarquista», Las Novedades, 26 de julio de 1888.
} 


\section{E L R E B E L D E}

Aล้อ 1. Numero 5.

NEW YORK, NOVIEMBRE 19, DE 1898 .

Suscripcion Voluntaria.

IMPORTANTE

EL EJERCITO SIGNIFICA TIRANIA

EL FIN DEL IMPERIO COLONIAL

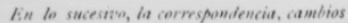

cuanto se refiera id RI. REBELDE, debe

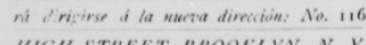

Cuenta la Historia que Rebospierre, al declarar Francia

a guerra á la Europa entera en los comienzos de la Gran

Revolución, se opuso á ella por creerla contraria á las

ertades del pueblo. Tras de la guerra-decia-viene ef

IIGII STRELT, BROOKLYN, N

privilegio.

Cabecera de El Rebelde, publicado en Brooklyn durante un breve periodo de tiempo.

\section{Publicaciones al servicio de la independencia de Cuba}

Tras los primeros periódicos que se editaron en español y estuvieron al servicio de la causa cubana, Nueva York facilitó la edición de una serie de publicaciones independentistas que se sucedieron a lo largo del siglo en pugna con los periódicos que defendían los intereses españoles. Como ocurría con la prensa españolista, también estos periódicos manifestaban la división existente entre los promotores de la emancipación cubana. Tras El Habanero y El Mensajero Semanal, que fueron pioneros en la defensa de la causa cubana en Nueva York, tal como hemos mencionado al comienzo de este artículo, otras muchas publicaciones periódicas nacieron en la metrópoli. Entre ellas podemos citar a La Verdad, sostenido por patriotas cubanos, que desde 1848 era distribuido gratuitamente para ganar adeptos a la causa ${ }^{20}$ o El Cometa y El Pueblo que vieron la luz en 1855. Estas cabeceras tuvieron una vida muy efímera y se iban sucediendo rápidamente e incluso salían de modo simultáneo. En una relación enviada en 1870 desde el Consulado de España en Nueva York, se apuntaba que los insurrectos publicaban en la ciudad hasta cinco periódicos distintos ${ }^{21}$ : La Revolución $^{2}$ que salía cada dos días y recibía la inspiración directa de la Junta Cubana de Nueva York primero (1868-1871) y de la Sociedad Auxiliadora de la Independencia de Cuba después (1871-1876), cuyos miembros tomaban parte casi exclusiva en la redacción. Este periódico se mantuvo ocho años con diversas cabeceras y directores y con una periodicidad variable ${ }^{22}$. El Diario Cubano que estaba editado por emigrados

\footnotetext{
${ }^{20}$ Salía a la calle los días 10, 20 y 30 de cada mes. La imprenta estaba en el número 704 de Church Street y la reacción en el 42 de Warren Street. Archivo Histórico Nacional, Ministerio de Asuntos Exteriores, $\mathrm{H} / 1984$.

${ }^{21}$ Despacho n. 47 del Consulado de Nueva York, Nueva York, 1 de junio de 1870, Archivo Histórico Nacional, Ministerio de Asuntos Exteriores, H/1985.

22 Los títulos que tuvo este periódico fueron variados, aunque siempre incluían el apelativo revolucionario: La Revolución: Boletín de la Revolución, (1868-1869), La Revolución. Cuba y Puerto Rico
} 
descontentos con los manejos de la citada Junta revolucionaria de la que contribuyeron a su formación, pero no pudieron formar parte. Comenzó a editarse en abril de 1870, cesando en el mes de junio siguiente. Su director, Rafael M. Merchán, era un escritor y poeta cubano que se dedicó a la enseñanza y al periodismo y defendió la independencia de Cuba desde el exilio. La Estrella de Cuba que era el órgano oficial de la Liga Cubana en los Estados Unidos y se publicó semanalmente a lo largo del año 1870 con una sección en inglés, The Cuban League of the United States, con la que se pretendía ganar adeptos entre los ciudadanos norteamericanos. La Voz del Pueblo que surgió para defender al general Quezada, cuya conducta censuraban los otros periódicos. Por último, El Demócrata que comenzó a publicarse en junio de 1870 y desde sus páginas se criticaba la actitud de la Junta Central por su incapacidad e inmovilismo. Este último permaneció en la calle durante un año bajo la dirección de Rafael Lanza, primero, y de Gabriel José Castillo después.

A estos periódicos le acompañaron una larga nómina de publicaciones cubanas que defendían la emancipación de la isla respecto de la monarquía española. Según Pedro Pascual, las revistas independentistas que se editaron en Nueva York sumaron un total de treinta y cinco títulos entre 1868 y 1898, lo que suponía el cuarenta por ciento de las publicaciones de este signo en América. Muy por detrás de Nueva York, le seguían La Habana, con dieciocho títulos, y Tampa con diez (Pascual, 1997). Aunque algunas tuvieron una vida fugaz, la presencia en la calle de estos periódicos muestra la vitalidad que el movimiento independentista cubano tenía en Manhattan, donde gozaban de una mayor libertad de prensa. Además, los contactos que esta metrópoli sostenía con el Caribe permitía la introducción de las publicaciones independentistas en Cuba donde la censura hacía más difícil la expansión de sus ideales.

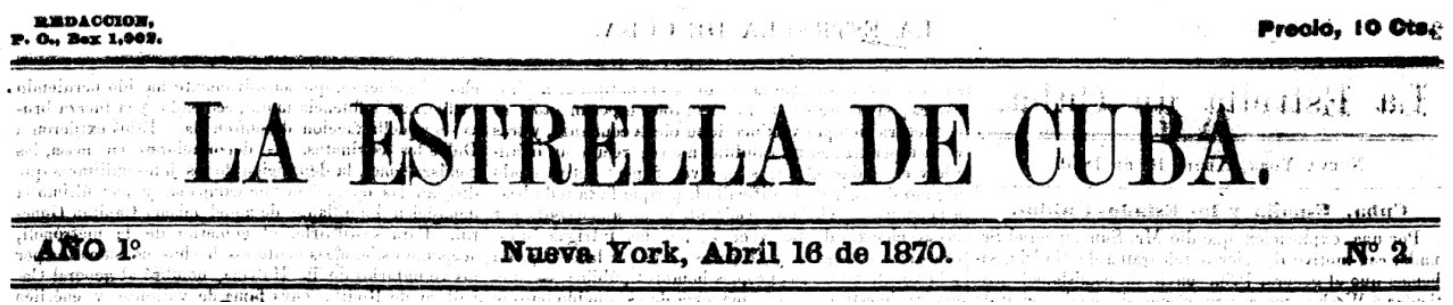

(1869), La Revolución (1869-1871), La Revolución de Cuba (1871-1873), La Revolución (1873-1874), La Revolución de Cuba (1875-1876). 


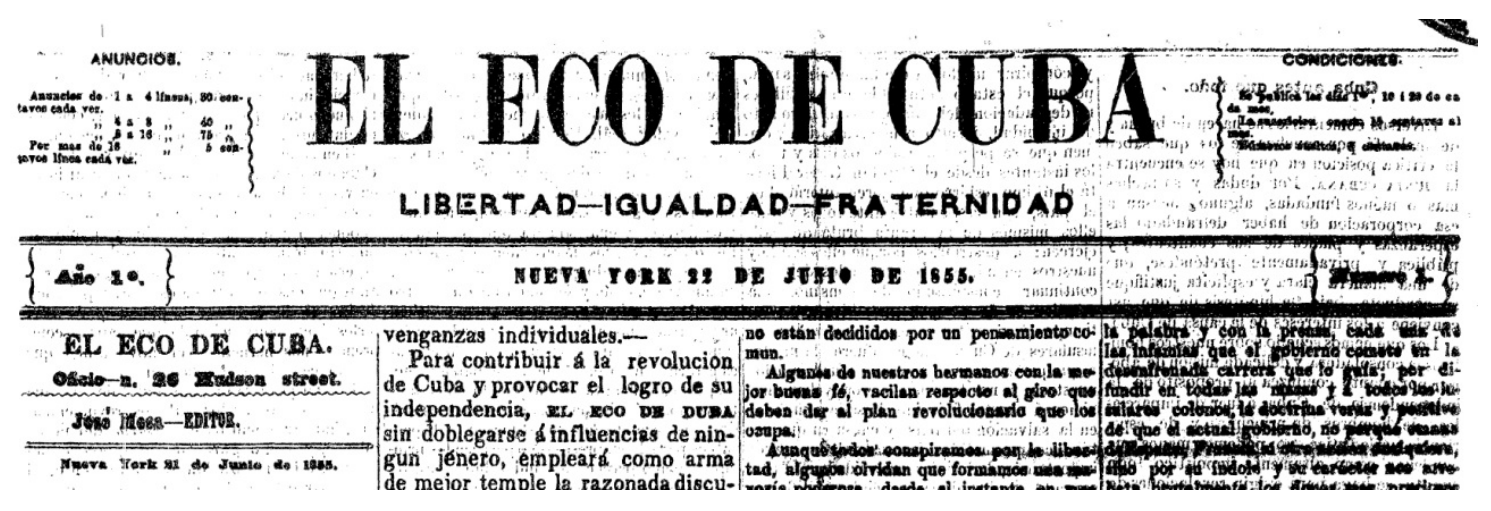

\section{Una línea periodística al servicio de los españoles}

Como puede verse, desde los años veinte del siglo XIX, disponemos de una línea editorial en defensa de los intereses españoles en Nueva York. No era una línea de perfiles nítidos y estables, sino cambiante, que se iba adaptando a los vaivenes políticos del siglo XIX e iba asumiendo también los perfiles de la vida norteamericana. Esta línea estuvo representada por periódicos como El Redactor, impreso durante los años del absolutismo monárquico de Fernando VII, La Crónica y El Cronista que nacieron durante la etapa de implantación del liberalismo y defendían los intereses españoles sobre las islas del Caribe y Las Novedades, que asumía una línea más comercial y acorde con los pueblos hispanoamericanos. Junto a estos periódicos de corte más político o españolista hubo otros que nacieron con unos intereses más empresariales como El Noticioso de Ambos Mundos o El Mercurio de Nueva York.

Por su parte, El Progreso estuvo vinculado al librepensamiento con una línea editorial muy distante de las otras publicaciones o La Llumanera de Nova York que defendía los intereses de la burguesía catalana. Entre ellos hubo diferencias e incluso discusiones que encendieron el debate periodístico, lo que muestra que la colonia española, además de exigua, estaba muy poco cohesionada. A finales de siglo, de modo paralelo al crecimiento del anarquismo en la ciudad, surgieron algunos periódicos de este signo como El Despertar o El Rebelde desde cuyas páginas se promovían los ideales de la lucha obrera entre los trabajadores hispanoparlantes de Nueva York, cuyas consignas eran muy distantes de aquellas defendidas por los españoles más acomodados que se habían integrado en la burguesía neoyorquina y defendían sus intereses comerciales desde los periódicos citados anteriormente. 
También la prensa cubana manifestaba una amplia variedad de opiniones en torno a la situación política y económica de la isla donde cada grupo era capaz de publicar su propio medio impreso. Esta pluralidad de opiniones entre los diversos grupos de hispanoparlantes hacía que los periódicos españoles editados en Nueva York constituyesen una paleta de pinceles muy dispersa y variopinta.

\section{Referencias bibliográficas}

ADAMS FERNÁNDEZ, C. (1992): "Cuba y su cultura durante el último cuarto del siglo XIX a través de La Ilustración Española y Americana", en Morales Saro, M.C. Y Llordén Miñambres, M. (editores), Arte, cultura y sociedad en la emigración española a América, Oviedo, Universidad de Oviedo, pp. 127-166.

ALMUIÑA FERNÁNDEZ, C. (1982): “La prensa periódica”, en Andrés-Gallego, J. (coord.), Historia general de España y América. Revolución y Restauración (1868-1931), Madrid, Rialp, vol. 16/1, pp. 135-154.

ÁLVAREZ, R. y GREDIAGA, I.G. (1863): Guía de Nueva York para uso de los españoles e hispanoamericanos, Nueva York, Imprenta, estereotipia y taller de encuadernación de John A. Gray.

AMEAL PÉREZ, A. (2015): “Nicanor Bolet Peraza en La Revista Ilustrada de Nueva York (1885-1890)" en Camino Real, no 7, pp. 77-91.

BARRERA-AGARVAL, M.H. (2018): “José G. García: adalid de los vínculos culturales entre España y los Estados Unidos", comunicación presentada en el $4^{\text {th }}$ International Conference on Historical Links between Spain and North America: New Cultural Cartographies, New York, April 11, 12 \& 13.

BELDAD, H.G. (1903): Guía ilustrada de Nueva York y sus alrededores, Nueva York, Louis Weiss \& Co., Impresores.

BOZAL FERNÁNDEZ, V. (1979): La ilustración gráfica del siglo XIX en España, Madrid, Comunicación.

BURGOA, J.J. (2011): “José Ferrer de Couto, historiador y periodista ferrolano", en Nalgures, no 7, pp. 9-26.

CABALLER DONDARZA, M. (2007): La narrativa española en la prensa estadounidense. Hallazgos, promoción publicación y crítica (1875-1900), Madrid, Iberoamericana. 
CADAFALCH, C., JULIAN, I. y SALCEDO, A. (1992), "Un ejemplo de ilustración catalana, la revista La Llumanera de Nova York", en Morales Saro, M.C. y Llordén Miñambres, M. (editores), Arte, cultura y sociedad en la emigración española a América, Oviedo, Universidad de Oviedo, pp. 103-125.

CASANOVAS I CODINA, J. (1989): “Introduction for Pedro Esteves's. Socialismo, anarquista: la ley, la violencia, el anarquismo, la revolución social", en Catalan Review. International Journal of Catalan Culture, no 3, pp. 9-44.

CASTAÑEDA, C.J. (2017): "Times of Propaganda and Struggle. El Despertar and Brooklyn's Spanish Anarchists, 1890-1905", en Goyens, T. (editor), Radical Gotham: Anarchism in New York City from Schwab's Saloon to Occupy Wall Street, Urbana, University of Illinois Press, pp. 77-99.

CHAMBERLIN V.A. y SCHULMAN, I.A. (1976) La Revista llustrada de Nueva York. History, Anthology, and Index of Literary Selections, Columbia, Missouri, University of Missouri Press.

DIANA, M.J. (1874): “Don José Ferrer de Couto", en La Ilustración Española y Americana, 22 de octubre de 1874, pp. 618-622.

GARCÍA GONZÁLEZ A. y ROLDÁN DE MONTAUD, I. (2016): “El españolismo radical en José Ferrer de Couto: México, Santo Domingo y Cuba", en Opatrný J. (coordinador), Proyectos políticos y culturales en las realidades caribeñas de los siglos XIX y XX, Praga, Universidad Carolina de Praga, pp. 65-75.

HERNÁNDEZ FUENTES, M.A. (2017): “Españoles y católicos en Manhattan a mediados del siglo XIX", en Cañero, J. (editor.), North America and Spain: transversal perspectives, pp. 214-227.

KANELLOS K. (editor) (2017): Recovering Hispanic Religious Thougt and Practice of the United States, Cambridge Scholar Publishing.

KANELLOS, N. y MARTELL, H. (2000): Hispanic periodicals in the United States, origins to 1960: A brief History and Comprehensive Bibliography, Houston, TX, Arte Público.

OLIVA NÚÑEZ, A.M. y SÁNCHEZ DEL COLLADO, A. (2016): "La prensa y la emigración cubana del siglo XIX en la Biblioteca Nacional de Cuba", en Revista de la Biblioteca Nacional de Cuba José Martí, no 2, pp. 123-139.

PASCUAL, P. (1997): “La prensa de España, Cuba, Puerto Rico y Filipinas y las guerras de independencia (1868-1898)", VI Encuentro de Latinoamericanistas Españoles. Disponible en Internet (4-7-2018): http://webs.ucm.es/info/cecal/encuentr/areas/historia/3h/prescuba.htm. 
QUINTANA SUÁREZ, R. (2011): "Fidel Castro y la prensa escrita: legado y contemporaneidad", Editorial Académica Española. Disponible en internet (5/5/2018): http://biblioteca.utec.edu.sv/siab/virtual/elibros_internet/55731.pdf

RUEDA HERNANZ, G. (2008): “Asociaciones y otras formas de relación de los españoles en Norteamérica", en Blanco Rodríguez, J.A. (editor), El asociacionismo en la emigración española a América, Salamanca, Universidad Nacional de Educación a Distancia, Junta de Castilla y León, pp. 235-276.

SCHULMAN, B.J. y ZELIZER, J.E. (editores) (2017): Media Nation: The Political History of News in Modern America, Filadelfia, University of Pennsylvania Press.

SUEIRO SEOANE, S. (2014): "Prensa y redes anarquistas transnacionales. El olvidado papel de J.C. Campos y sus crónicas sobre los mártires de Chicago en el anarquismo de lengua hispana" en Cuadernos de historia contemporánea, 36, pp. 259-295.

- (2017): “Anarquistas españoles en Estados Unidos: Pedro Esteve y el periódico El Despertar de Nueva York (1891-1902)", en Cañero, J. (editor), North America and Spain: Transversal perspectives, Nueva York, Escribana books, pp. 76-86.

- (2018): "El periódico El Esclavo de Tampa y la red anarquista hispano-cubana en los Estados Unidos a finales del siglo XIX", en Aguasaco, C. (editor), Transatlantic gazes: studies on the Historical links between Spain and North America, Alcalá de Henares, Servicio de Publicaciones de la Universidad de Alcalá de Henares, pp. 121-140.

VARELA-LAGO, A.M. (2008): Conquerors, Immigrants, Exiles: The Spanish Diaspora in the United States (1848-1948), Tesis doctoral, University of California, San Diego.

- (2018): “La prensa será nuestra mejor arma. The Activities of the New Agency of the Spanish Legation in Washington during the Cuban War of Independence", comunicación presentada en el 4th International Conference on Historical Links between Spain and North America: New Cultural Cartographies, New York, April 11,12 \& 13.

VILAR GARCÍA, M. (2008): El español, segunda lengua en los Estados Unidos: de su enseñanza como idioma extranjero en Norteamérica al bilingüismo, Murcia, Ediciones de la Universidad de Murcia.

VILAR, M. y VILAR, J.B. (1996): La prensa en los orígenes de la enseñanza del español en los Estados Unidos (1823-1833), Murcia, Servicio de Publicaciones. Universidad de Murcia. 